\title{
A VISÃO DO ESTUDANTE DE ENFERMAGEM SOBRE O DESENVOLVIMENTO DO ESTÁGIO CURRICULAR NO PERÍODO NOTURNO
}

\author{
Isabel Cristina dos Santos Oliveira*
}

OLIVEIRA, I.C. dos S. A visão do estudante de enfermagem sobre o desenvolvimento do
estágio curricular no período noturno. Rev.Esc.Enf.USP, v. 30 n. p.73-81,abr. 1996

Estudo preliminar baseado no método qualitativo visando conhecer a opinião dos estudantes de Enfermagem do $7^{\circ}$ periodo sobre o desenvolvimento do estágio no período noturno. Foram identificados nos trinta relatos os seguintes aspectos: importância da experiência; participação da enfermeira e da equipe de saúde; $e$ diferença entre o período diurno e notumo. A maioria dos relatos demonstrou que a experiência foi válida devido apenas ao relacionamento da enfermeira e da equipe de saúde, e que não houve uma contribuição efetiva no aprendizado. Os relatos destacaram a diferença entre a assistência de enfermagem nos dois periodos. Concluiu-se que é necessário um debate amplo do corpo docente e discente sobre os objetivos do estágio no período noturno como uma das experiências curriculares para a formação profissional.

UNITERMOS: Enfermagem. Período Noturno. Estudante.

\section{INTRODUÇÃO}

No ensino de Enfermagem, o estágio curricular tem uma importância indiscutivel na formação do estudante e está previsto pelo Conselho Federal de Educação (CFE) através da Resolução CFE n 4/72.

O currículo da Escola de Enfermagem, à qual pertencem os estudantes, sujeitos desse estudo, tem dois programas cujo objetivo é prestar assistência a clientes hospitalizados em duas instituições universitárias, um hospital geral e um hospital pediátrico.

\footnotetext{
* Professor Adjunto do Departamento de Enfermagem Médico-Cirúrgica da Escola de Enfermagem Anna Nery da Universidade Federal do Rio de Janeiro
}

Rev.Esc.Enf.USP, v.30, n.1, p.73-81, abr. 1996. 
$\mathrm{Na}$ implantação desse currículo, foi estabelecido que no $7^{\circ}$ semestre ocorreriam quatro dias de estágio, no periodo noturno, distribuidos em um dia para o hospital pediátrico e três dias para o hospital geral.

No decorrer dos anos, devido a inúmeros fatores levantados pelos professores e alunos, dentre eles: seleção das experiências, relação numérica supervisor/aluno, remuneração do supervisor e outros, o estágio no período noturno foi reduzido para três noites e posteriormente para duas noites.

Pela vivência profissional, acreditamos que o estágio dos alunos de Enfermagem no período noturno, é uma das experiências que devem ser proporcionadas nas diferentes grades curriculares dos Cursos de Graduação em Enfermagem e Obstetrícia das escolas do país. Como apontam SOBRAL et al. ${ }^{7}$, a evolução e/ou involução de uma doença, como também os problemas administrativos, não escolhem hora para acontecer.

Por isso, a nossa preocupação, enquanto docente de enfermagem, em proporcionar aos nossos alunos experiências nos diferentes períodos em que se dá a assistência de enfermagem nas organizações hospitalares.

Porém, em nossa experiência como docente de Enfermagem num dos programas curriculares do $7^{\circ}$ periodo, que tem por objetivo prestar assistência integral à criança hospitalizada, constatamos, com freqüência, que os estudantes de Enfermagem questionam a finalidade de desenvolver estágio no período noturno como uma das experiências curriculares.

Diante da vulnerabilidade do fato e da escassez de trabalhos referentes ao tema, justifica-se um estudo a fim de refletir sobre o assunto.

Os objetivos são os seguintes:

- conhecer a opinião dos estudantes de Enfermagem do $7^{\circ}$ período sobre o desenvolvimento do estágio no período noturno;

- proporcionar subsídios para uma avaliação adequada do estágio no período noturno como uma experiência curricular.

\section{METODOLOGIA}

O presente estudo analisou os relatos de 30 estudantes de Enfermagem, do $7^{\circ}$ período do Curso de Graduação em Enfermagem e Obstetrícia de uma escola de Enfermagem pertencente a uma Universidade Federal no Município do Estado do Rio de Janeiro. Os relatos foram obtidos durante o estágio no período noturno num Hospital Pediátrico Universitário, no $1^{\circ}$ e $2^{\circ}$ semestres de 1988.

Cabe ressaltar que o estudo não considerou a especificidade do campo de prática, que no caso é a pediatria, pois o objetivo inicial é questionar a atividade - estágio no período noturno e, posteriormente, em outro estudo, 
aprofundar a questão da assistência integral à criança hospitalizada no período noturno.

Para organização do conteúdo obtido seguiu-se a orientação de LÜDKE; ANDRE $E^{5}$, segundo a qual a análise dos dados qualitativos implica na organização de todo o material, dividindo-o em partes, relacionando essas partes e, em seguida, identificando os aspectos relevantes.

Considerando a seqüência citada, os seguintes temas foram agrupados:

- importância da experiência (estágio no período noturno);

- participação da enfermeira e da equipe de saúde; e

- diferença entre o período diurno e noturno.

Finalmente, os temas foram analisados à luz do referencial tebrico.

\section{APRESENTAÇÃO DOS RESULTADOS}

\section{Importância da experiência (estágio no período noturno)}

Em relação ao desenvolvimento do estágio no serviço noturno, vinte e dois relatos consideraram a experiência válida e proveitosa, destacando aspectos tais como: "dificuldades orgânicas" da equipe e também dos pacientes e familiares; conhecimento das rotinas do setor, no período noturno; complementação do aprendizado; oportunidade de prestar assistência integral ao paciente; e ampliação da experiência prática e do aprendizado.

"A experiência foi válida e importante uma vez que pude verificar as dificuldades orgânicas que a equipe vive juntamente com os pacientes e familiares."

"O plantão foi válido por ter proporcionado uma nova experiência no sentido de aprendermos na prática as normas do serviço noturno."

"O serviço noturno realizado foi por nós considerado válido, por ampliar a experiência e o aprendizado..."

Outros aspectos foram mencionados pelos estudantes de Enfermagem e merecem ser transcritos. Cinco estudantes enfocam que o período noturno foi uma atividade cansativa apesar de válida.

"Plantão noturno é um serviço cansativo..."

"Achei o plantão extremamente cansativo..."

Três dos estudantes de Enfermagem tiveram uma opinião contrária em relação à importância do estágio no período noturno.

"O contato com a criança foi bom e proveitoso, porém questiono a importância deste $\mathrm{SN}$, pois as atividades são praticamente as mesmas desempenhadas de dia no estágio normal." 
"Em relação às intercorrências durante o $\mathrm{SN}$, notei que nada foi relevante comparado ao estágio realizado durante o dia, questionando-se a importância desta prática."

\section{Participação do supervisor e da equipe de saúde}

A supervisão dos estudantes de Enfermagem, durante o estágio no período noturno, 6 feita por uma enfermeira do hospital, que exerce a função de supervisão, e que recebe uma remuneração para exercer esta atividade. Porém, é exigido que não haja sobreposição do horário de acompanhamento do estágio com o horário desta enfermeira na escala de serviço.

Nos relatos dos estudantes de Enfermagem, a participação da enfermeira foi considerada de diferentes formas: contribuição para o aprendizado; auxílio nas atividades; disponibilidade; cap acidade e habilidade favorecendo o relacionamento; solícita a todo o momento; facilidade da criatividade e decisão dos alunos; e supervisão adequada permitindo a tomada de decisões do aluno.

"Gostaria de ressaltar a presença da enfermeira que estava nos supervisionando, que contribui bastante para o nosso aprendizado."

"A enfermeira supervisora desempenhou seu papel de maneira adequada, demonstrando capacidade e habilidade, favorecendo com isso um excelente relacionamento."

Treze relatos dos estudantes de Enfermagem não mencionam a presença da enfermeira, e apenas dois dos relatos apontam a necessidade da presença de um docente no período noturno.

Entretanto, para dezesseis estudantes de Enfermagem foi relevante o relacionamento interpessoal com a enfermeira, não mencionando com a mesma ênfase a sua contribuição no aprendizado.

Quanto à participação da equipe de saúde, apenas oito estudantes referem-se à equipe, comentando que o relacionamento e a interação foram excelentes e o grupo funcionou como uma equipe.

\section{Diferença entre período diurno e noturno}

Dos relatos elaborados pelos trinta estudantes de Enfermagem, doze enfatizaram a diferença entre a assistência prestada ao paciente no período diurno e noturno, sendo que sete verificaram diferença, dois pouca diferença e três nenhuma diferença.

Os relatos que diferenciam os dois períodos destacam os seguintes aspectos: nítida diferença entre o período diurno e noturno em relação aos procedimentos a serem executados, conhecimento das rotinas do período noturno e as vantagens do referido período tais como: menor envolvimento e tensão no desenvolvimento das atividades, bem como maior interação com o paciente. 
"Notei nitidamente a diferença entre o $\mathrm{SN}$ e $\mathrm{SD}$, pois o $\mathrm{SD}$ é bem mais agitado devido aos procedimentoss a serem executados..."

"Plantão noturno traz determinadas vantagens tais como: pouco movimento (entra e sai)... livra-nos de trabalhar tensos e preocupados."

"O período de 12 horas de estágio é válido para vivenciar experiências em relação a rotina dos plantões, principalmente no serviço noturno."

Cinco estudantes de Enfermagem comentaram sobre o sono que é um aspecto marcante para a equipe de saúde, principalmente a enfermagem, durante as atividades no período noturno.

Para dois estudantes, o sono não foi um obstáculo a ser superado devido às experiências anteriores como estágio extracurricular e voluntário, bem como plantões com vínculo empregatício.

"Por já ter experiências anteriores, o sono não foi um problema."

"A questão do sono não foi relevante para mim, pois já tive experiências anteriores."

Cabe ressaltar que o aspecto "sono" foi destacado nos relatos devido a orientação dada pelos professores quanto às normas da Escola de Enfermagem, a qual pertencem os estudantes, que não permitem o descanso durante o período noturno. este aspecto não será discutido no estudo porque, antes, merece uma discussão cuidadosa em relação à justificativa para tal norma.

No que concerne à aprendizagem proporcionada pelo estágio no período noturno, os relatos dos estudantes de Enfermagem foram bastante deficientes na medida em que os termos subjetivos da avaliação não foram explicitados tais como: contribuição do enfermeiro para o aprendizado, complementação do aprendizado, ampliação da experiência, melhor desempenho na execução dos procedimentos e outros.

\section{DISCUSSÃO DOS RESULTADOS}

Considera-se que e fundamental questionar se o estágio no período noturno é uma das experiências fundam entais na formação profissional, bem como fazer o corpo docente refletir sobre a importância ou não desta experiência como um requisito curricular no Curso de Graduação em Enfermagem.

SOBRAL et al. ${ }^{7}$ ponderam que:

"A assistência de enfermagem desenvolvida no serviço noturno (SN) deve dar continuidade ao que é planejado no serviço diurno (SD), onde um maior número de profissionais podem avaliar de forma mais acurada as necessidades dos pacientes." 
Os estudantes de Enfermagem demonstraram pelos relatos que foi válida a experiência do estágio no período noturno, contudo não foi enfocado pelos mesmos que a assistência de Enfermagem ao paciente é um processo contínuo e que desta maneira as experiências curriculares não são atividades isoladas.

Os relatos enfocam a todo momento uma posição unilateral do estudante de Enfermagem, em confronto com o que deveria ser esperado por ele quando, durante o curso, se ressalta a assistência integral à clientela nas 24 horas.

"Em relação às intercorrências durante o $\mathrm{SN}$, notei que nada foi relevante comparado ao estágio realizado durante o dia, questionando-se a importância desta prática."

Não se pretende discutir de quem é a responsabilidade por esta lacuna no processo ensino/aprendizagem, porém é necessária uma reflexão por parte de todos os envolvidos: professores, estudantes e inclusive equipe de enfermagem.

De acordo com LANTHIER ${ }^{4}$, o papel desempenhado pelo professor de Enfermagem no desenvolvimento da prática profissional é um dos elementos que contribui de forma marcante para que ocorra um aprendizado eficiente.

Por outro lado, NORONHA ${ }^{6}$ comenta que no desenvolvimento de qualquer atividade, o ser humano sofre influências de fatores internos e/ou externos fundamentais na eficácia de toda ação individual. Estes fatores constituem a chamada motivação, que no ambiente de trabalho e de ensino assume importância crucial e está intimamente ligada ao desenvolvimento mental, emocional, profissional e social do indivíduo.

No que diz respeito à supervisão do estágio no período noturno, observamos que dezesseis relatos enfatizaram como bom o relacionamento com a enfermeira, porém não destacaram a contribuição efetiva da mesma no aprendizado dos estudantes.

"A presença da supervisora foi muito boa, pois mostrou-se à disposição sempre que solicitada."

"A enfermeira se mostrou solícita a todo momento."

A supervisão direta do estágio é uma das normas da Escola de Enfermagem à qual pertencem os estudantes. A diferença é que o supervisor do estágio no período noturno não é um docente de Enfermagem, mas um enfermeiro do serviço selecionado e remunerado exclusivamente para a referida atividade.

Não se pode constatar claramente pelos relatos dos estudantes de Enfermagem, porém se questiona a seguinte situação: somente o professor tem papel preponderante no processo ensino/aprendizagem.

Quanto à participação da equipe de saúde, a maioria dos relatos dos estudantes destacaram apenas o relacionamento interpessoal. 
"O relacionamento com a equipe de Enfermagem foi excelente."

"A interação com a equipe multiprofissional nesse plantão foi uma das melhores que participei."

CARVALHO ${ }^{1}$ enfoca que o interrelacionamento dos estudantes em estágio com os profissionais da saúde exerce grande influência na formação do estudante que poderá aprender através dos exemplos bons ou maus.

Entretanto, os relatos dos estudantes não são explícitos em relação à contribuição da equipe multiprofissional para o aprendizado.

Por outro lado, CASTRO et al. ${ }^{2}$ constatam que nas experiências de aprendizagem há pouca participação do pessoal dos serviços, enquanto é quase nula a participação de docentes nas atividades dos serviços.

Em sete relatos, os estudantes de Enfermagem destacaram a diferença entre a assistência prestada à clientela no período diurno e noturno, entretanto, a diferença limitou-se apenas ao aspecto rotinas. Um dos principais objetivos do estágio no período noturno, que é identificar as necessidades biopsicossociais do paciente nas 24 horas do dia, não foi relatado.

$O$ fato merece uma reflexão por parte dos docentes, principalmente daqueles que orientam os estudantes de Enfermagem sobre o estágio no período noturno, como também uma discussão ampla com todos os docentes para uma avaliação precisa desta atividade no currículo de graduação.

Os relatos dos estudantes de Enfermagem não possibilitaram uma consideração em profundidade no que se refere à diferença entre o período diurno e noturno, pois este aspecto não foi explicitado com clareza. A tentativa de diferenciação não foi substancial.

Por outro lado, a fadiga que é um dos fatores que interferem na assistência de Enfermagem no período diurno e se agrava no noturno, foi citada.

"Plantão Noturno é um serviço cansativo e desgastante."

"O plantão apesar de cansativo, decorreu tranqüilamente."

"Achei o plantão extremamente cansativo."

"O sono não foi um problema", conforme os relatos de dois estudantes de Enfermagem. A justificativa foi baseada em experiências anteriores, sugerindo que estes estudantes conhecem de alguma forma (estágio extracurricular) as modificações orgânicas decorrentes da atividade no período noturno.

FIGUEIREDO; MACEDO ${ }^{3}$ enfocam que uma das necessidades humanas básicas é o sono, e que o não atendimento à esta necessidade, durante e após a jornada de trabalho noturno, acarreta condições desfavoráveis ao estado físico e mental do indivíduo.

Apesar dos relatos serem deficientes para se discutir a experiência de 
aprendizagem proporcionada pelo estágio no período noturno, alguns estudantes de Enfermagem disseram que "o serviço noturno serviu como uma complementação do aprendizado", "melhor desempenho (habilidade) na execução dos procedimentos", "útil ao nosso aprendizado".

Estes aspectos citados podem servir como ponto de partida para uma discussão ampla entre os professores e os estudantes de Enfermagem quanto à contribuição do estágio no período noturno para a formação profissional.

\section{CONSIDERAÇÕES FINAIS}

O estudo preliminar sobre o estágio no período noturno baseado nos relatos dos estudantes serviu como reflexão de mais uma experiência proposta pelo corpo docente de Enfermagem, partindo talvez de vivências individuais.

A experiência docente tem demonstrado que explicitar os objetivos das atividades dos programas curriculares é um fator primordial para o adequado desenvolvimento das metas previstas, como também proporcionar uma visão realística do exercício profissional, já que é imprescindível que não ocorra um descompasso entre a formação e a prática profissional.

CASTRO et al. $^{2}$ ressaltam que:

"O ensino da Enfermagem não deve divorciar-se do contexto prático, sob o risco de não lograr o domínio de competências esperadas e de fracassar no alcance dos objetivos educacionais."

Ainda, segundo NORONHA ${ }^{6}$, no ensino da Enfermagem um dos pontos de grande importância $\theta$ a correlação com o real, isto $\theta$, a aquisição dos conhecimentos científicos a partir do desempenho das habilidades práticas.

O método utilizado no estudo foi o qualitativo, o que facilitou a proposta de questionar a experiência que vem sendo desenvolvida pelos estudantes de Enfermagem do $7^{\circ}$ período de uma escola de Enfermagem pertencente a uma universidade federal do Município do Estado do Rio de Janeiro.

Através do estudo concluímos que:

- a análise dos 30 (trinta) relatos não foi suficiente para uma conclusão mais precisa sobre a situação, pois as opiniões foram superficiais e fragmentadas;

- os professores necessitam melhor estruturar a atividade - estágio no período noturno - quanto aos objetivos, clientela, carga horária e supervisão em campo de prática; $e$

- é necessário um debate, do corpo docente e discente, sobre os objetivos do estágio no período noturno como uma das experiências curriculares para a formação profissional. 
OLIVEIRA, I.C. dos S. The view of the college students nursing about the development of the curriculary experience on the night shift. Rev.Esc.Enf.USP, v.30, n.1, p.73-81, Apr. 1996

This preliminary work was based in the qualitative method, about the opinion of the College students nursing in the seventh $\left(7^{\text {th }}\right)$ stage of the course about the development of the curriculary experience on the night shift. Thirty (30) relates were identifyed in the respective aspects: importance of the experiences, relationship between overseer nurse and multidisciplinary health care team; difference between day shift and night shift. The most part of the related demonstrates that it's been valided and they've given emphasis, only, in relationship between overseer nurse and multidisciplinary health care team, without emphasizing the effective contribution on the practice knowledge. The relatings emphasized the difference among the shifts. It follows that is necessary an extense discussion of the teachers, nursing body and college students nursing body, under the effective objectives of the practice curriculary experience for professional qualification.

UNITERMS: Nursing. Night Shift. Student.

\section{REFERÊNCIAS BIBLIOGRÁFICAS}

1. CARVALHO, A.C. Consideraçð̃es sobre o ensino de campo na enfermagem. Rev. Bras. Enf., v. 25, n. 5, p. $149-53,1972$.

2. CASTRO, I.B. et al. Reflexão sobre a prática de enfermagem no Brasil e na América Latina: implicações educacionais. Rev. Bras. Enf., v.35, n.3/4, p.185-91, 1982.

3. FIGUEIREDO, N.M.A.; MACEDO, M.C.S. Fadiga: intercorrência na assistência de enfermagem. /Apresentado no 36 Congresso Brasileiro de Enfermagem, Belo Horizonte, $1984 /$

4. LANTHIER, M.G.C. O professor de enfermagem: atuação em campo clínico. Rev. Bras. Enf., v.37, n.1, p.2-11, 1984.

5. LƯDKE, M; ANDRÉ, M.E.D.A. Pesquisa em educação: abordagens qualitativas. São Paulo, EPU, 1986.

6. NORONHA, R. Motivação no ensino e na assistência de enfermagem. Rev. Bras. Enf., v. 38, n. 1, p.70-5, 1985.

7. SOBRAL, V.R.S. et al. O oficial $x$ oficioso no serviço noturno: a quem interessa esta prática. Cad. Enf., n.1, p.7-16, 1988. 